\title{
RETINAL VEIN OCCLUSION AND GLAUCOMA* TONOGRAPHIC STUDY OF THE INCIDENCE OF GLAUCOMA AND OF ITS PROGNOSTIC SIGNIFICANCE
}

BY

\author{
SALME VANNAS AND AHTI TARKKANEN \\ From the Eye Hospital of the University of Helsinki, Finland
}

Present thinking about the relations between central retinal vein occlusion and glaucoma derives mainly from the pioneer work of Verhoeff (1913), Salzmann (1933), and Duke-Elder $(1940,1957,1959)$. Since their papers on this subject many reports have been added to the literature. Recently, Landolt (1958) has published his work on histology and Dobree (1957) clinical studies on the incidence of central retinal vein occlusion in glaucoma patients.

The incidence of glaucoma has been studied at this hospital in a series of patients with retinal vein occlusion. Both central vein and branch occlusions were included, and since most of these subjects have been treated as inpatients at our hospital, the prognosis of the glaucoma also entered into the question. To the best of our knowledge, no similar studies employing tonography have been published.

\section{Material}

Between 1949 and 1959, 186 patients were treated for retinal vein occlusion at the Helsinki University Eye Hospital. When they were admitted to the ward for occlusion treatment the routine glaucoma investigation consisted of measuring the ocular tension with an ordinary Schiötz X-tonometer, ophthalmoscopy, and plotting of the visual fields with the Goldmann perimeter. If glaucoma was suspected, round the clock ocular tension curves were obtained and gonioscopy and the appropriate provocative tests were performed. No tonography was done at that time, since it is only recently that this procedure has become available to us. The data on these patients before this study was started are shown in Table I.

TABLE I

PREVIOUS DIAGNOSIS OF GLAUCOMA IN 186 CASES OF RETINAL VEIN OCCLUSION WITHOUT USE OF TONOGRAPHY

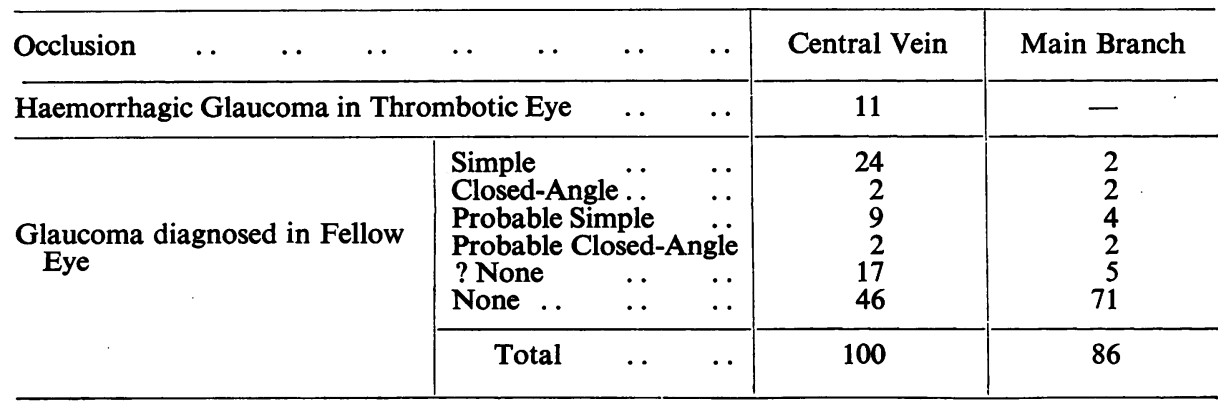

* Received for publication October 23, 1959. 
The rather low incidence of glaucoma is conspicuous; only 28 cases were diagnosed out of 186 . When the present study was planned a request to attend for a follow-up examination was sent to every patient. It was found that 33 patients had died, and 24 could not be traced, but a total of 129 patients reported for examination; 71 had had an occlusion of the central retinal vein and 58 a branch occlusion.

\section{Procedure}

Tonography was carried out with a Mueller electronic tonometer later linked to a Leeds and Northrup Speedomax Type G recorder. A daily calibration was obtained with a Tonometer Micro-Gauge. Considerable attention was paid to the tonographic technique. All the tracings were done by one of us (A.T.), and the patient was allowed time to relax thoroughly before the procedure was started. The tonometer was applied to the cornea with as little disturbance to the patient as possible. Scale readings below 4 were not accepted; if a reading of 4 or less was obtained with a given weight, a change to the next higher weight was always made (Moses, 1959). Estimates for intra-ocular pressure and outflow facility were obtained from the 1955 Friedenwald calibration tables. Gonioscopy was performed with a Goldmann gonio-lens, while the patient sat at the Haag-Streit slit lamp.

Impairment of aqueous outflow with the presence of open angles was interpreted as suggestive of simple glaucoma. The water-drinking test and the ratio of intraocular pressure to outflow facility were used (Becker and Christensen, 1956) in evaluating these cases.

If the angles were found to be narrow and there were records of previous acute attacks, closed-angle glaucoma was diagnosed. Otherwise, provocative tests were carried out to test the angle-closure mechanism, using the dark-room test (Foulds, 1957) and the mydriatic test (Becker and Thompson, 1958). A 50 per cent. decrease of outflow in the former or a 25 per cent. decrease in the latter was regarded as a significant change.

\section{Results \\ I. Incidence of Glaucoma (Table II, opposite)}

\section{(A) Simple Glaucoma}

(1) Central Retinal Vein Occlusion.-28 patients in this group had simple glaucoma in both eyes, and two more patients very probably had the same diagnosis, an incidence of 42 per cent. When the occlusion developed, there was a general trend in these eyes towards lower tensions, some being $5 \mathrm{~mm}$. $\mathrm{Hg}$ or more lower than the fellow eyes. This phenomenon, which was attributed to hyposecretion, sometimes made it difficult to find the right diagnosis. However, within a few weeks, simple glaucoma was manifest as regards tension also. In seven cases haemorrhagic glaucoma had developed later in the eye which had suffered central vein occlusion, and four of the glaucomatous fellow eyes had gone blind from glaucoma. It would seem reasonable to suppose that the occlusion would develop in the eyes which gave lower outflow values, but no correlation between occlusion and outflow was observed. In many instances, on the contrary, it was the fellow eye that showed a lower outflow value and was more damaged by glaucoma. 
TABLE II

RESULTS OF TONOGRAPHY COMBINED WITH SUITABLE PROVOCATIVE TESTS IN THE DIAGNOSIS AND CLASSIFICATION OF GLAUCOMA IN CASES OF RETINAL VEIN OCCLUSION

\begin{tabular}{|c|c|c|c|c|c|c|c|}
\hline \multirow{2}{*}{$\begin{array}{l}\text { Occlusion } \\
\text { Eye }\end{array}$} & \multirow{2}{*}{$\frac{\cdots}{\ldots}$} & \multirow{2}{*}{$\cdots$} & \multirow{2}{*}{$\frac{\cdots}{\ldots}$} & \multicolumn{2}{|c|}{ Central Vein } & \multicolumn{2}{|c|}{ Main Branch } \\
\hline & & & & Thrombotic & Fellow & Thrombotic & Fellow \\
\hline \multirow[t]{2}{*}{$\begin{array}{l}\text { Type of } \\
\text { Glaucoma } \\
\text { Diagnosed }\end{array}$} & $\begin{array}{l}\text { Simple } \\
\text { Closed-Angle } \\
\text { Mixed-Simple a } \\
\text { Angle } \\
\text { Probable Simple } \\
\text { Haemorrhagic }\end{array}$ & $\begin{array}{l}. \\
\ddot{\text { and }} \mathrm{Clo} \\
. \\
\ldots \\
.\end{array}$ & $\begin{array}{l}\because \\
\ddot{\text { sed}} \\
\ldots \\
\ldots \\
. .\end{array}$ & $\begin{array}{l}2 \\
1 \\
9\end{array}$ & $\begin{array}{r}2 \\
2 \\
-\end{array}$ & E & 二 \\
\hline & \multicolumn{2}{|c|}{ Total with Glaucoma } & .. & 36 & 34 & 7 & 7 \\
\hline \multicolumn{2}{|c|}{ No Glaucoma } & .. & .. & 35 & 37 & 51 & 51 \\
\hline Total & .. & .. & .. & 71 & 71 & 58 & 58 \\
\hline
\end{tabular}

(2) Branch Occlusion.-Simple glaucoma in both eyes was found in six patients out of 58, an incidence of 10 per cent. None of these eyes had developed haemorrhagic glaucoma.

\section{(B) Closed-angle Glaucoma}

(1) Central Retinal Vein Occlusion.-Four cases were diagnosed, and two patients had the mixed variety of simple and closed-angle glaucoma. In three cases the occlusion was discovered at the time of an acute attack and these patients therefore presented diagnostic difficulties when it came to excluding haemorrhagic glaucoma. An acute rise in intra-ocular pressure was found to be one of the factors probably contributing to the vein occlusion (Posner, 1958).

\section{(2) Branch Occlusion.-One case.}

(C) Haemorrhagic Glaucoma.-This had developed in eleven eyes, nine of which were seen at the follow-up examination, and two of which were diagnosed previously.

These were blind eyes with very flat tracings in tonography. Nine of the fellow eyes had simple glaucoma. This incidence of 82 per cent. simple glaucoma is impressive, not only from the theoretical point of view but also clinically since these were the only seeing eyes for this group of patients. Early diagnosis and control of the glaucoma would not only preserve the vision but would probably have a prophylactic value in saving these eyes from vein occlusion. In two of the fellow eyes repeated provocative water-drinking and mydriatic tests had failed to reveal any evidence of glaucoma. 


\section{Prognostic Significance of Glaucoma in Central Vein Occlusion}

VIsion.-This part of our study was confined to the cases with central vein occlusion, which were divided into five groups according to the visual acuity:

I. $1 \cdot 3$ to 0.6 ,

II. $0 \cdot 5-0 \cdot 1$,

III. c. $15 \mathrm{ft}-$ c. $3 \mathrm{ft}$, good peripheral field

$I V$. c. $15 \mathrm{ft}-$ c. $3 \mathrm{ft}$, peripheral field absent

$V$. Haemorrhagic glaucoma.

The results are seen in Table III and in the Figure (opposite). Groups I and II made up 70 per cent. of the glaucoma-free series, and only 41 per cent. of the glaucoma series. Furthermore, only two eyes in the glaucoma-free series developed haemorrhagic glaucoma, compared with seven eyes in the glaucoma series. These findings indicate that the combination of central retinal vein occlusion and glaucoma suggests not only a poorer end-result but also that such eyes are in greater danger of developing intractable haemorrhagic glaucoma.

TABLE III

VISUAL RESULTS OF CENTRAL RETINAL VEIN OCCLUSION IN PATIENTS WITH AND WITHOUT PRIMARY GLAUCOMA

\begin{tabular}{c|c|c|c|c|c|c}
\hline \multirow{2}{*}{ Primary Glaucoma } & \multicolumn{5}{|c|}{ Grade of Vision } & \multirow{2}{*}{ Total Cases } \\
\cline { 2 - 7 } & I & II & III & IV & V & \\
\hline Absent & 15 & 11 & 9 & - & 2 & 37 \\
\hline Present & 4 & 10 & 6 & 7 & 7 & 34 \\
\hline
\end{tabular}

AGE.-The average age in the glaucoma series was $66 \cdot 2$ yrs (range 42 to 85 ), and in the glaucoma-free series 53.6 yrs (range 30 to 88). Table IV (overleaf) indicates that the end-results are fairly similar in both series for patients under 65 years of age. Above the age of 65,76 per cent. (19 out of 25 ) had both central retinal vein occlusion and glaucoma, indicating that the poor end-result in the older age groups can be attributed to glaucoma rather than to old age per se. Moreover, it is conceivable that the presence of glaucoma would explain the poor recovery and slow resorption in these eyes. This contradicts the common belief that old age in itself means a poor prognosis in retinal vein occlusion.

TREATMENT.-The usual long-term therapeutic regime, mainly with heparin, employed for most of our patients has been thoroughly reviewed previously (Vannas and Orma, 1957). The cases not treated with anticoagulants were seen for consultation in the medical department in any event. Table V (overleaf) shows that the visual outcome was better in the treated group and that the eyes showing no evidence of glaucoma in this group had a much better prognosis. 


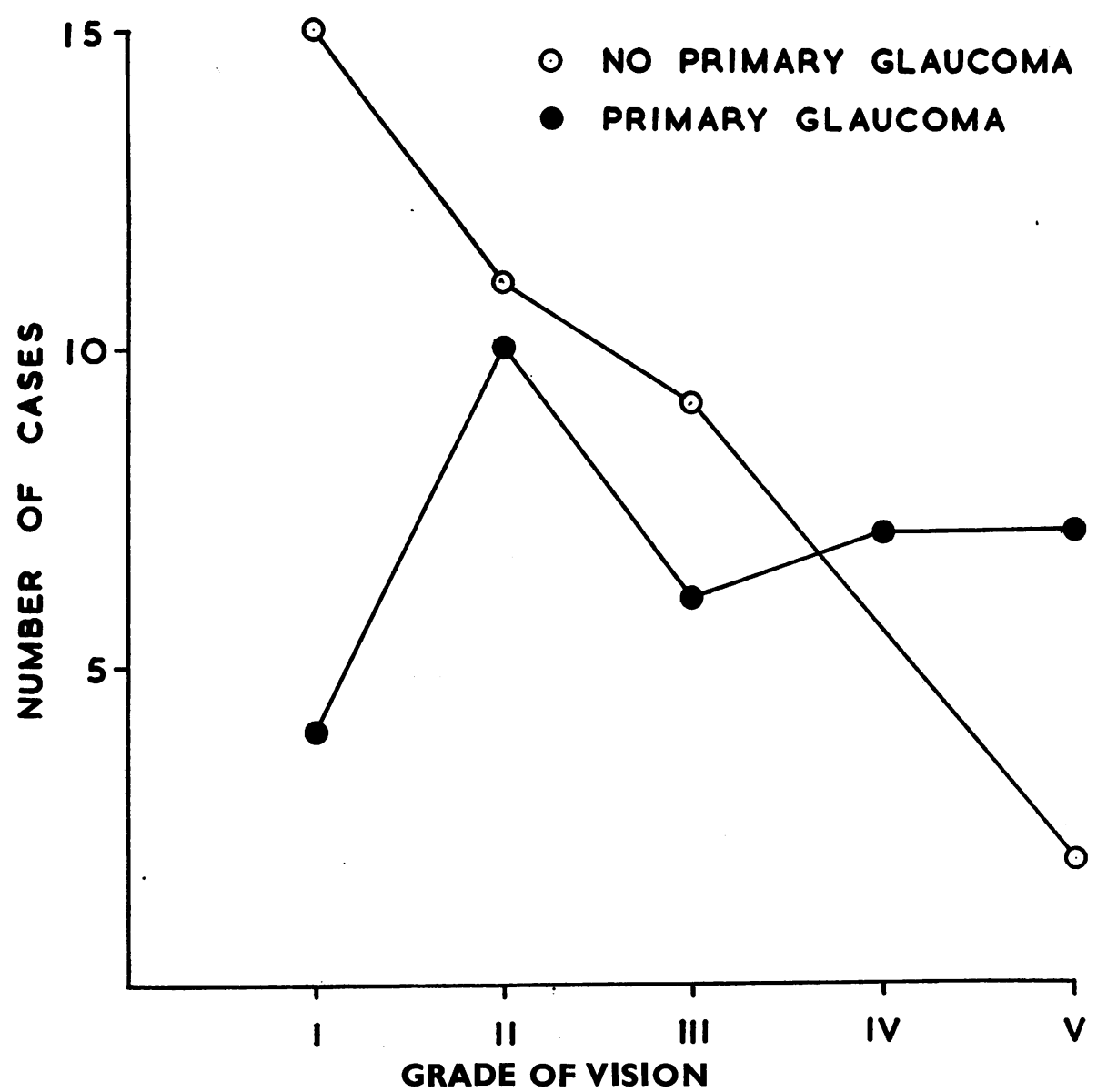

FigURE.-Prognosis in cases of central retinal vein occlusion with and without primary glaucoma.

\section{Discussion}

The most striking finding in our series is the 42 per cent. incidence of simple glaucoma in those with central retinal vein occlusion. Furthermore, taking the age group above 65 years, three out of four patients had simple glaucoma in addition to the venous occlusion. Although in many cases the glaucoma was diagnosed afterwards, the poor aqueous outflow in both eyes indicated that the impairment of outflow had been going on for years before the occlusion occurred. To the best of our knowledge, no similar findings have been published. Becker and Post (1951) found a 23 per cent. incidence of simple glaucoma in a series of 44 patients with central retinal vein occlusion, but their report was made before the introduction of tonography. The 10 per cent. incidence of simple glaucoma in those with branch occlusion is similar to that usually found in patients of the same age with the same methods. 
TABLE IV

CORRELATION OF AGE AND PROGNOSIS IN CASES OF CENTRAL RETINAL VEIN OCCLUSION

\begin{tabular}{|c|c|c|c|c|c|c|c|}
\hline \multirow{2}{*}{$\begin{array}{l}\text { Primary } \\
\text { Glaucoma }\end{array}$} & \multirow{2}{*}{$\begin{array}{c}\text { Age Group } \\
\text { (yrs) }\end{array}$} & \multicolumn{5}{|c|}{ Grade of Vision } & \multirow{2}{*}{$\begin{array}{l}\text { Total } \\
\text { Cases }\end{array}$} \\
\hline & & I & II & III & IV & $\mathrm{V}$ & \\
\hline \multirow[t]{2}{*}{ Absent } & $\begin{array}{l}31-50 \\
51-65 \\
66-88\end{array}$ & $\begin{array}{l}7 \\
6 \\
2\end{array}$ & $\begin{array}{l}4 \\
7\end{array}$ & $\begin{array}{l}2 \\
3 \\
4\end{array}$ & & 2 & $\begin{array}{r}15 \\
16 \\
6\end{array}$ \\
\hline & Total & 15 & 11 & 9 & & 2 & 37 \\
\hline \multirow[t]{2}{*}{ Present } & $\begin{array}{l}31-50 \\
51-65 \\
66-88\end{array}$ & $\begin{array}{l}1 \\
2 \\
1\end{array}$ & $\begin{array}{l}1 \\
5 \\
4\end{array}$ & $\begin{array}{l}1 \\
5\end{array}$ & $\begin{array}{l}2 \\
2 \\
3\end{array}$ & $\begin{array}{l}1 \\
6\end{array}$ & $\begin{array}{r}4 \\
11 \\
19\end{array}$ \\
\hline & Total & 4 & 10 & 6 & 7 & 7 & 34 \\
\hline
\end{tabular}

TABLE V

VISUAL RESULTS OF CENTRAL RETINAL VEIN OCCLUSION IN PATIENTS WITH AND WITHOUT GLAUCOMA, BY THERAPY GIVEN

\begin{tabular}{|c|c|c|c|c|c|c|c|}
\hline \multirow{2}{*}{ Therapy } & \multirow{2}{*}{$\begin{array}{l}\text { Primary } \\
\text { Glaucoma }\end{array}$} & \multicolumn{5}{|c|}{ Grade of Vision } & \multirow{2}{*}{$\begin{array}{l}\text { Total } \\
\text { Cases }\end{array}$} \\
\hline & & I & II & III & IV & $\mathrm{V}$ & \\
\hline \multirow{2}{*}{$\begin{array}{l}\text { Anticoagulant } \\
\text { and Antisclerotic }\end{array}$} & $\begin{array}{l}\text { Absent } \\
\text { Present }\end{array}$ & $\begin{array}{r}18 \\
4\end{array}$ & $\begin{array}{l}11 \\
10\end{array}$ & $\begin{array}{l}5 \\
4\end{array}$ & 5 & $\begin{array}{l}1 \\
4\end{array}$ & $\begin{array}{l}35 \\
27\end{array}$ \\
\hline & Total & & & & & & 62 \\
\hline \multirow{2}{*}{$\begin{array}{l}\text { Medical without } \\
\text { Anticoagulants }\end{array}$} & $\begin{array}{l}\text { Absent } \\
\text { Present }\end{array}$ & 2 & $\begin{array}{l}3 \\
2\end{array}$ & $\begin{array}{l}8 \\
3\end{array}$ & 5 & $\begin{array}{l}1 \\
5\end{array}$ & $\begin{array}{l}14 \\
15\end{array}$ \\
\hline & Total & & & & & & 29 \\
\hline
\end{tabular}

Moore (1924) described two cases of haemorrhagic glaucoma following occlusion of the central retinal vein, in which the fellow eye had simple glaucoma. Similar findings have been reported by Gradle (1937), Sugar (1942), and Wessely (1947). The high incidence of simple glaucoma in fellow eyes has been emphasized by Becker (1957), Higgitt (1957), and Leydhecker (1956). Our findings of 82 per cent. simple glaucoma in the fellow eye agree with theirs. From the clinical standpoint it should be borne in mind that, when these patients consult an ophthalmologist because of the redness and severe pain often encountered in eyes with haemorrhagic glaucoma, it is necessary, besides making a thorough examination of other aetiological factors usually present, to make complete tests for glaucoma in the fellow eye, while the therapeutic pain-relieving measures are directed toward the affected eye. The importance of such investigations and treatment for these practically one-eyed persons cannot be over-emphasized. Further studies by one of us on the aetiology of haemorrhagic glaucoma are to be published elsewhere (Vannas, 1960). 
An acute rise in pressure in an eye with retinal vein occlusion is very easily described as "secondary to occlusion". Our five cases of primary closedangle glaucoma prove that this is not always true. In addition, since the therapeutic approach to this type of glaucoma is different (Duke-Elder, 1957, 1959), glaucoma should always be looked for if the angles are narrow, or particularly, if puzzling rises in pressure occur.

\section{Summary and Conclusions}

(1) A 42 per cent. incidence of simple glaucoma was found in a series of 71 patients with central retinal vein occlusion. Of those above 65 years of age, three patients out of four had simple glaucoma in both eyes in addition to the venous occlusion.

(2) Simple glaucoma was seen in 58 cases of branch occlusion (10 per cent.).

(3) Five cases of primary closed-angle glaucoma were diagnosed.

(4) Among the eleven patients with unilateral haemorrhagic glaucoma nine had simple glaucoma in the opposite eye.

(5) The patients with central retinal vein occlusion treated with our longterm anticoagulant therapy had a better visual outcome than the untreated patients, and those with no evidence of glaucoma had a more favourable general prognosis.

(6) Discovery of central vein occlusion or unilateral haemorrhagic glaucoma calls for exhaustive examination for primary glaucoma. This is most accurately done by the use of tonography in association with gonioscopy and the appropriate provocative tests. The established cases of glaucoma should be carefully treated and here again tonography offers a useful method of testing the adequacy of therapy.

\section{REFERENCES}

BECKER, B. (1957). A.M.A. Arch. Ophthal., 58, 862.

- and ChRISTENSEN, R. E. (1956). Ibid., 56, 321.

and Post, L. T. (1951). Amer. J. Ophthal., 34, 677. and THOMPSON, H. E. (1958). Ibid., 46, 305.

DobreE, J. H. (1957). Trans. ophthal. Soc. U.K., 77, 229.

DUKE-ELDER, S. (1940). "Text-book of Ophthalmology", vol. 3, p. 2578. Kimpton, London. (1957). Trans. ophthal. Soc. Aust., 17, 12. (1959). Ann. Oculist. (Paris), 192, 26.

FouLds, W. S. (1957). Brit. J. Ophthal., 41, 200.

GradLE, H. S. (1937). Amer. J. Ophthal., 20, 1125.

HIGGITT, A. C. (1957). Brit. J. clin. Pract., 11, 745.

LANDOLT, E. (1958). Ophthalmologica (Basel), 135, 427.

LEYDHECKER, W. (1956). Docum. ophthal. (Den Haag), 10, 174.

MOORE, R. FOSTER (1924). "Retinal Venous Thrombosis". Brit. J. Ophthal., Monograph Suppl. 2. Pulman, London.

Moses, R. (1959). A.M.A. Arch. Ophthal., 61, 373.

POSNER, A. (1958). Eye, Ear, Nose Thr. Monthly, 37, 688.

SalzmanN, M. (1933). "Glaukom und Netzhautzirkulation". Suppl. No. 15 to Z. Augenheilk.

SugAr, H. S. (1942). Arch. Ophthal. (Chicago), 28, 587.

VANNAS, S. (1960). I Europ. Cong. Ophthal., Athens, 1960. Ophthalmologica (Basel).

and OrMA, H. (1957). A.M.A. Arch. Ophthal., 58, 812.

VERHOEFF, F. H. (1913). Ibid., 42, 145.

WESSELY, K. (1947). v. Graefes Arch. Ophthal., 148, 111. 